\title{
Developing the rotational synchronous teaching (RST) model: Examination of the connected classroom climate
}

Yanhong Li,

Central China Normal University

\author{
Harrison Hao Yang \\ State University of New York, Central China Normal University
}

Jason MacLeod,

Central China Normal University

Jinjun Dai

Central China Normal University

\begin{abstract}
The multiple synchronous smart classroom learning environment (MSSC) is an alternative educational context that describes several active learning classrooms, connected through synchronous broadcasting technology. MSSC provides conceptually new capabilities to maximise both student learning and instructor efficiency. However, MSSC lacks an empirically validated instructional model, which limits effectiveness, particularly in relation to student interaction. Therefore, this study designed, developed, and implemented the rotational synchronous teaching (RST) model: a practical instructional approach for simultaneously teaching large student audiences, while maintaining smaller interactive classroom atmospheres. The RST model was tested in a mixed method research design that relied on survey $(n=305)$ and interview $(n=8)$ data of college students collected at the conclusion of the spring semester 2017. The effects of this RST model on student connected classroom climate obtained results matching previous research in traditional face-to-face classroom contexts. These preliminary findings indicate that the MSSC can effectively cultivate social interaction among students in a large instructional context with an approapriate instructional approach. The results of this study also suggest the need to expand future research toward comparative methodologies that examine additional variables, including academic achievement.
\end{abstract}

\section{Introduction}

Technology-supported learning environments have emerged to address two fundamental challenges in education: (1) maximising student learning, and (2) increasing instructor teaching efficiency (Lai, 2011). While many developments have emphasised the former, few practical solutions have addressed the human resource constraints of instruction without reducing or eliminating face-to-face social interaction in the classroom. Baepler, Walker, and Driessen (2014) suggested that the only way to teach large active audiences without increasing instructor commitment was to "blend and flip; ... split the [class] into three parts that meet only once a week rather than three times each week, and move online a large portion of the course's learning activities, which were previously conducted face-to-face” (p. 227). While this approach has proven effective, there is no scalability beyond current capacity. That is to say, instructors' time distribution has already reached maximum efficiency. This study develops and examines an alternative instructional approach for large lecture hall instructions, which conceptually extends the teaching efficiency of the instructor via synchronous computer-mediated integration of multiple smart classrooms.

Several interpretations of the smart classroom concept exist (cf. Baepler et al., 2014; MacLeod, Yang, Zhu, \& Li, 2018; Shen, Wu, \& Lee, 2014; Shi et al., 2003). This study defines a smart classroom as a face-toface (F2F) technology-supported learning environment which integrates technology beyond the traditional technology-enhanced lecture classroom (e.g., computers, projectors, instructor-controlled visual display, etc.) in ways that increase students' active learning processes while emphasising flexibility for different types of instructional delivery. Smart classrooms typically dedicate multiple interactive whiteboards (IWB), that are compatible with mobile devices, for student group work. Smart classrooms also integrate web cameras to record instruction for synchronous broadcasting or asynchronous playback. When more than one smart classroom is connected via synchronous computer-mediated communication, a new learning 
environment emerges: the multiple synchronous smart classroom learning environment (MSSC) (e.g., Alelaiwi et al., 2015; Pishva \& Nishantha, 2008). The present study is based on this interpretation of MSSC.

The smart classroom emerged to address the first challenge of maximising student learning. As a result, the prevalence of smart classroom instruction has increased, particularly in China, where the government is sponsoring implementation at all levels of education (Huang, Yang, \& Hu, 2012; Ministry of Education [MOE], 2017). However, when utilised in a traditional manner, smart classrooms provide as little advantage for addressing the second challenge of instructor efficiency as individual classroom spaces. That is to say, each smart classroom still requires an instructor, which only maintains traditional human resource capacity. This dilemma stimulated the emergence of MSSC. The MSSC leverages the synchronous broadcasting capabilities of smart classrooms, thus allowing an instructor to simultaneously teach large audiences that are distributed among several smaller spaces. Such large audiences would traditionally have been taught via large lecture halls, which often hosts negative conditions for social interaction.

Thus, MSSC conceptually provides an opportunity to relieve the unresolved twenty-first century issues of human resource constraints in education. The issue of qualified instructor shortages has been wellrecognised throughout the world (Aragon, 2016; Ingersoll \& Perda, 2009). This is particularly the case in China, where rapid expansion of higher education has left an unmanageable demand for qualified instructors. Shortages of instructors have been most problematic in compulsory courses, with large, demanding audiences, as well as general studies courses. As a result, there has been a trend toward class size expansion and consequently, the use of large lecture halls to cope with student learning demands. However, large lecture halls are not well suited for providing students with individually attention. Furthermore, these scenarios impose challenges for even the most experienced instructors, who may struggle to provide timely feedback and pursue any teaching strategies beyond lecturing (Hancock, 2010). In some of the worst circumstances, lecture hall scheduling cannot satisfy the full capacity of the enrollment in composulsory and/or general courses. This dilemma provides an example of why students are sometimes forced into enrolling in courses with instructors who may lack experience or who are underqualified for teaching a specific academic discipline. Hence, technology-supported learning environments such as MSSC is gaining popularity for its ability to allow more students the access to high-quality instructors (Yang, Zhu, \& MacLeod, 2016; Yang, Zhu, \& MacLeod, 2018).

In contrast, MSSC requires that traditional instructors' roles be divided between a leading instructor, as the content expert; and teaching assistants, as classroom facilitators. Additionally, F2F instruction is partially replaced by synchronous computer-mediated communication. The change that computer-mediated communication imposes on personal relationships is a well-recognised issue of educational research (Walther \& Park, 2002). For instance, whenever an instructor is physically absent, concerns relating to student perception and instructional effectiveness arise. Research has suggested that peer relationships exert more influence on classroom participation than the relationship between instructors and their students (Fassigner, 1996, 1997; Sideliner \& Booth-Butterfield, 2010). Connected classroom climate (CCC) describes student-to-student relationships and has been positively associated with cognitive learning (Frisby \& Martin, 2010; Prisbell, Dwyer, Carlson, Bingham, \& Cruz, 2009), self-regulated learning (Sidelinger \& Booth-Butterfield, 2010), and affective learning (Frisby \& Martin, 2010; Johnson, 2009). These related studies have attracted attention for an examination of CCC in technology-supported environments that lack traditional F2F instructional presence (e.g., MacLeod, Yang, Zhu, \& Shi, 2017; Xu, Yang, \& MacLeod, 2018; Yang, Feng, \& MacLeod, 2018). However, to our knowledge, no study has examined CCC in the MSSC learning environment. Additionally, no empirically validated instructional approaches exist that would guide teaching in MSSC. These are very urgent issues. Without evidence that the MSSC can effectively support social interaction among students, it is not possible to inform the administrative decision-making of educational institutions at the strategic levels. Furthermore, without documentation of successful instructional models, replication of MSSC may not be possible. Thus, the objectives were to:

1. design, develop, and implement a practical instructional model for the MSSC so as to cope with the well-documented challenges of computer-mediated instruction, and

2. examine the effects of the implementation of the instructional model on CCC among Chinese college students. 


\section{Methodology}

\section{Development of the rotational synchronous teaching (RST) model}

\section{Rationale}

The rotational synchronous teaching (RST) model is our proposed instructional approach for the MSSC. The RST model was developed to increase instructor efficiency by supporting the synchronous instruction of large audiences located in connected smaller classrooms. However, the larger a student audience becomes, the less possibilities exist for social interaction among students. This issue provides justification for an examination of CCC within the RST model of instruction.

\section{Description}

The RST model encompasses three core concepts:

1. Flipped classroom instruction, a blended learning technique (Bonk \& Graham, 2005), is used to integrate smart classroom and cloud classroom (MacLeod, Yang, Zhu, \& Shi, 2017) learning components. Flipped classroom instruction provides an opportunity to accommodate students' individual learning paces. Additionally, these integrated processes allow the instructor to assess students before and after class, so as to most effectively customise instruction.

2. The F2F teaching presence of instructors changes on a rotational schedule, in an effort to humanise the synchronous computer-mediated instructional process. For instance, if eight classroom groups were participating, the instructor would have delivered one F2F session and seven synchronous computer-mediated sessions to each classroom after eight instructional sessions. Figure 1 illustrates the instructor's rotational schedule and the functional design of each smart classroom.

3. Instructional responsibilities are divided between a specialised instructor and teaching assistants to maintain interactive and supportive classroom atmospheres. The specialised instructor designs and delivers instructional content to all classes and oversees all other instructional processes. Meanwhile, teaching assistants manage the individual classroom processes of discussion, practice, and reflection.
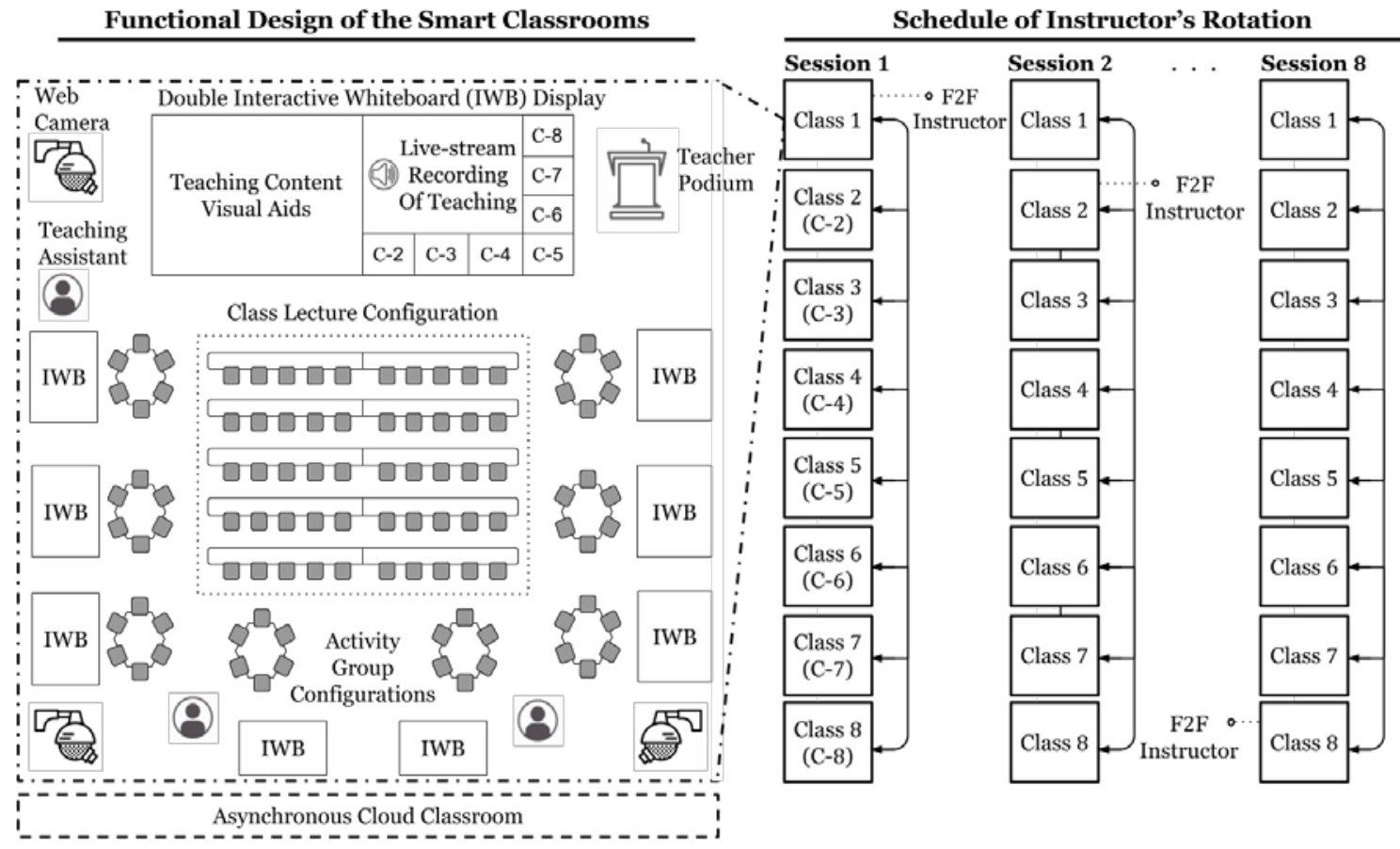

Figure 1. Overview of the RST model in the MSSC

Note: IWB = interactive whiteboard; C = class; F2F = face-to-face; Each classroom offers the same components as illustrated for Class 1. 
Theoretical framework

The RST model is based upon Gagné's $(1965,1985)$ theory of instruction, which suggests that learning is cumulative, and different types of instructional events are required to stimulate different types of intentional learning outcomes. As part of his theory of instruction, Gagné proposed nine instructional events to guide the internal processes of learners: (1) gain attention, (2) inform learner of the objective, (3) stimulate recall of prior information, (4) present information, (5) provide guidance, (6) elicit performance, (7) provide feedback, (8) assess performance, and (9) enhance retention and transfer. The instructional processes of the RST model are based on Gagné's nine instructional events.

\section{Functional design}

As shown in Figure 1, each smart classroom has two main IWBs on the front wall. The left IWB is used to display the learning content, while the right IWB shows a synchronous video of the instructor teaching, as well as a synchronous video of each ancillary classroom that receives computer-mediated instruction. Within each smart classroom, smaller IWBs are also mounted on exterior walls for group work activities. Group work IWBs support Bluetooth compatibility with students' mobile devices, which enables immediate visual support for students' social interactions through participation with learning connects and other related Internet resources. Teaching assistants facilitate computer-mediated instructional delivery in ancillary classrooms to provide support in-between instructor rotations. Essentially, processes are designed to maximise students' access to the specialised skills of a content expert (the instructor), while delegating less specialised instructional responsibilities of classroom facilitation and management to teaching assistants in order to maintain smaller classroom atmospheres.

\section{Instructional process}

As shown in Figure 2, the RST model integrates Gagné's (1965, 1985) nine instructional events between the physical and cloud classrooms. Additionally, the organisation of the nine instructional events is distributed in relation to the time of their implementation (pre-class, during-class, and post-class). In the RST model, all physical classroom instructional events are synchronous, while all cloud classroom instructional events are asynchronous.

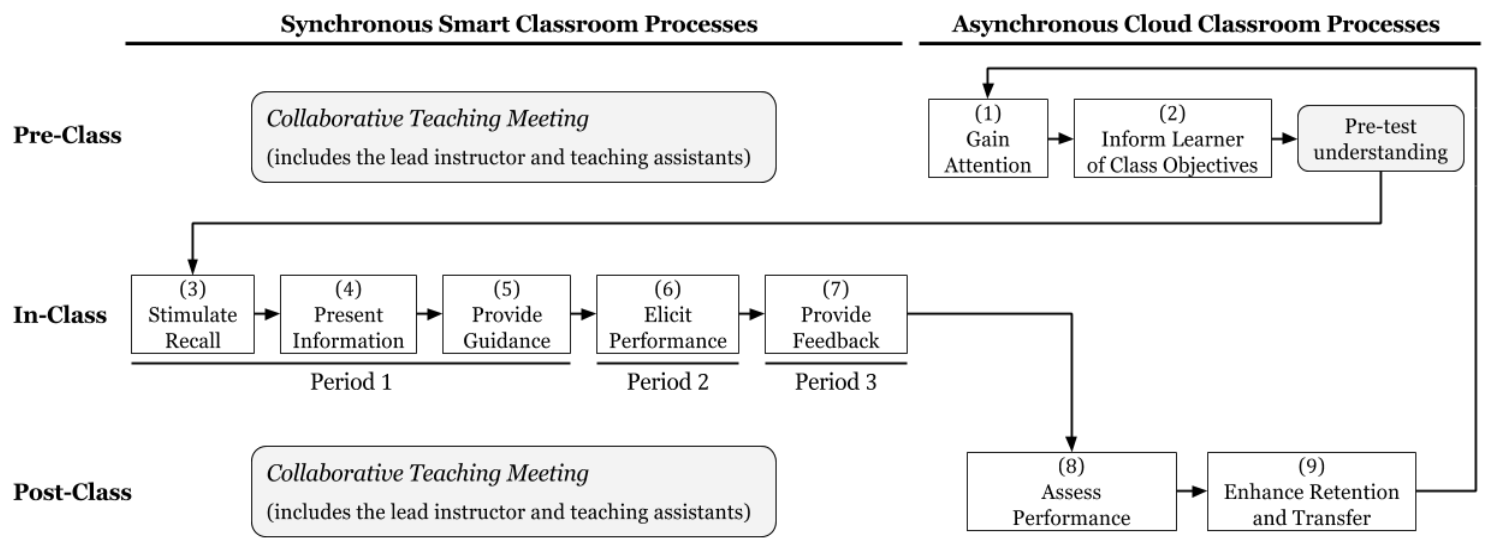

Figure 2. Instructional processes of the RST model

Before class, the learning topic and related objectives are introduced to students in the cloud classroom. The cloud classroom refers to a ubiquitous virtual space that hosts computer-mediated communication and the related processes of a shared formal learning experience (MacLeod, Yang, Zhu, \& Shi, 2017). In addition, before class, students complete an assessment in the cloud classroom individually to provide the instructor with insights into students' pre-existing knowledge. These flipped classroom processes allow students to prepare themselves prior to class, which eases the burden of accommodating large-scale audiences simultaneously. These processes also allow the instructor to identify topics that students need the most assistance with during instructional time.

In class, instruction is divided into three time periods. The first section provides a lecture-based learning experience. The second session engages students in small group activities that require the application of the knowledge provided by the instructor in the previous period. The third session re-organises students back into the full class group to discuss challenges and provide feedback where necessary. During the class, the 
instructor manages the process of content presentation, while teaching assistants manage the processes of discussion, practice, and reflection.

After the class, students are tasked with an assignment or quiz in either the cloud classroom or the real classroom to assess their understand of new concepts. This assessment provides insight into the key topics that the instructor should recall during the introduction to the next instructional session. In addition, to support individual differences in student learning, video recordings of instruction are made available in the cloud classroom to further enhance retention and provide support when student absences occur.

In addition to the sequence of nine instructional events, the RST model requires organisational processes between the lead instructor and teaching assistants. For example, before the class begins, the whole instructional team will meet to discuss the instructional content, roles and responsibilities of individuals, potential challenges that students may encounter and recommended pedagogical strategies for facilitating the collaborative instructional process. After the class, the whole team meets, again, for reflective discussion. This meeting primarily focuses on ways for improving future processes and provides an opportunity to keep the lead instructor informed as to the specific progress of each class.

\section{Division of instructor's roles and responsibilities}

When implementing the RST model, roles and responsibilities must be divided between the lead instructor and the teaching assistants. From a practical perspective, the division of roles and responsibilities may vary between applications depending on factors such as subject norms, the technological competence of the lead instructor and the instructional competence of the teaching assistants. Generally, the lead instructor will use his or her strength in content knowledge and his or her teaching experience to organise the course curriculum, design course schedules and deliver instruction. The lead instructor will also, typically, design and develop the processes of student assessment. As shown in Figure 3, the lead instructor manages the responsibilities of instructional delivery to eight classes in a MSSC learning environment.
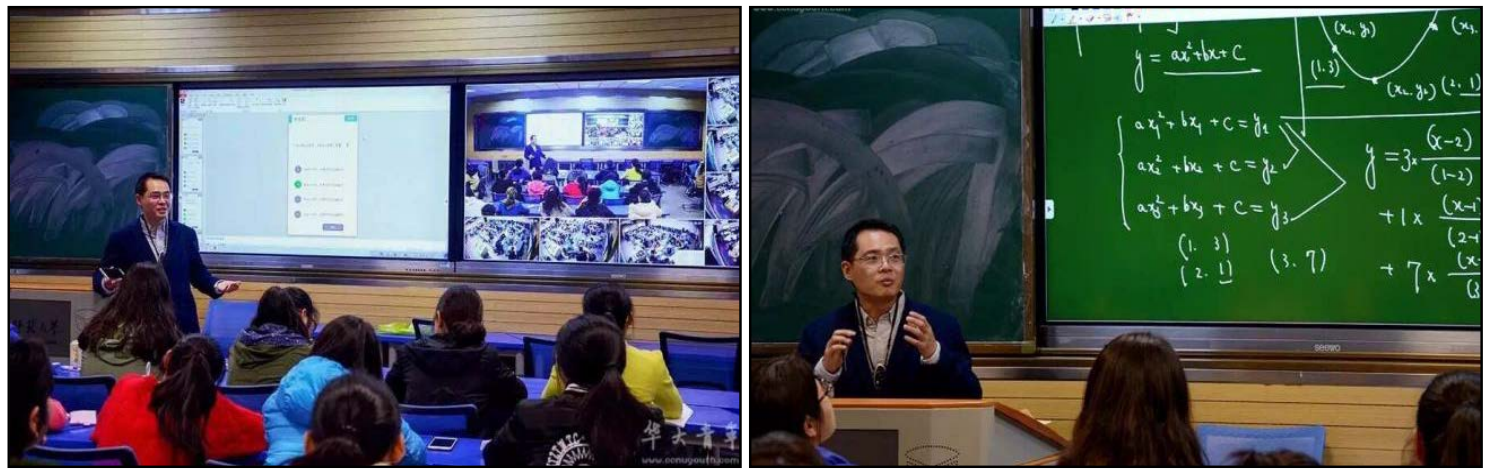

Figure 3. Representative examples of the lead instructor's teaching role

In the left photo, the right-side IWB display shows a synchronous video presentation of the instructor's lecture, which is being transmitted to seven ancillary classes. This display also shows smaller synchronous video presentations of each connected ancillary classroom. The right photo demonstrates how the second IWB is used to synchronously display the visual course content (in this case, handwritten mathematical equations) to all classes.

To complement the lead instructor, teaching assistants typically arrange classroom activities and facilitate all non-specialised or administrative roles and responsibilities of the educational processes. These responsibilities may include supporting small group activities, analysing pre- and post-class student performance data, tracking student attendance and participation as well as managing the organisation of students' learning materials in the cloud classroom. As shown in Figure 4, teaching assistants support the instructional processes of each individual classroom in the MSSC learning environment. 

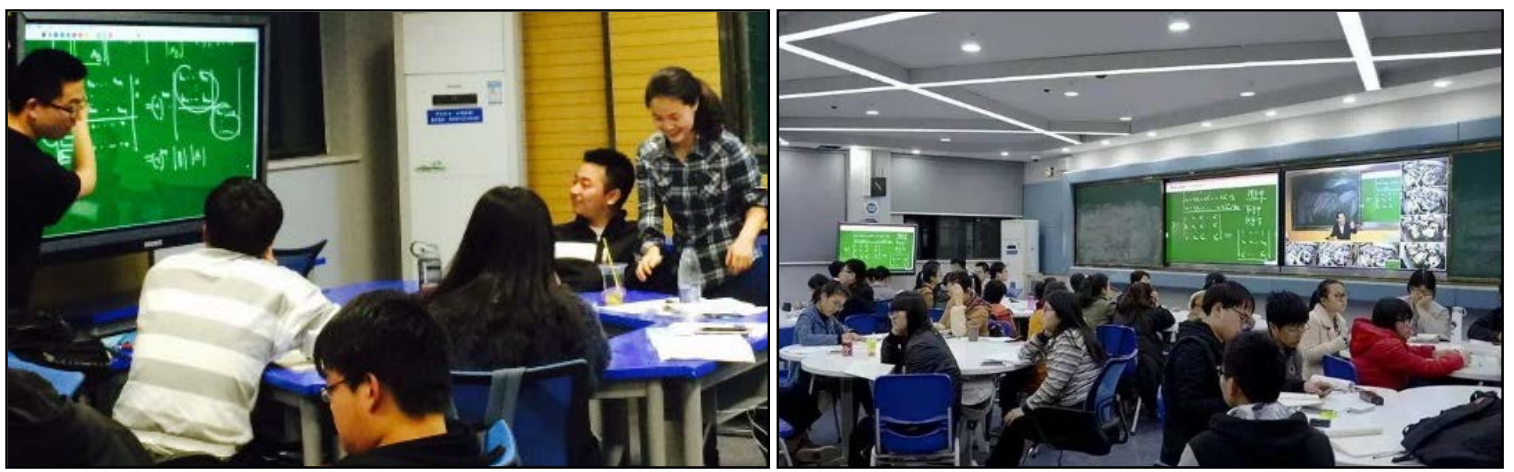

Figure 4. Representative examples of the teaching assistants' facilitation role

In the left photo, teaching assistants are actively participating in the instructional process of small group practice activities. In the right photo, multiple IWB displays are used to synchronously connect classrooms without F2F instructor.

\section{Evaluation of CCC in the RST model}

It is crucial that researchers, policy makers, and practitioners possess knowledge of empirically validated instructional models. To examine CCC within the RST model of instruction, this section: (1) summarises the related CCC research to conceptualise a research model with research questions and hypotheses, (2) overviews the current research methodology, and (3) presents the results, discussion, and analyses.

\section{Research question}

CCC is defined as "student-to-student perceptions of a supportive and cooperative communication environment in the classroom" (Dwyer et al., 2004, p. 267). CCC is particularly important in the RST model of instruction because the majority of students follow their instructor through synchronous computermediated communication. This procedural change of instruction centralises student-to-student communication and interaction to in the learning process. Considerable research has shown that CCC is positively associated with students' cognitive, affective, and self-regulated learning in F2F environments (Frisby \& Martin, 2010; Johnson, 2009; Sidelinger \& Booth-Butterfield, 2010). Additionally, research has shown that instructor presence is not associated with CCC (Frisby \& Martin, 2010; Sidelinger, Bolen, Frisby, \& McMullen, 2011). This notion has been empirically supported in comparative studies exploring instructional delivery method in F2F and blended learning approaches (e.g., Ritter, Polnick, Fink, \& Oescher, 2010; Xu et al., 2018), which found similar levels of CCC regardless of the time instructors spend with students. To further provide a benchmark of existing research, Table 1 illustrates the results of peerreviewed studies examining Dwyer et al.'s (2004) interpretation of CCC. GoogleScholar was used to identify all studies that cited Dwyer et al., and studies which empirically utilised Dwyer et al.'s instrument in higher education were examined to provide a benchmark for this study. As notated in Table 1, most studies examined F2F environments; however, some previous research has explored online, and blended classrooms of higher education. Results were reported in two ways: item mean scores (average of item responses for the 18 item CCC construct) or scale mean scores (sum of responses for the 18 item CCC construct). 
Table 1

Summary of peer-reviewed CCC findings

\begin{tabular}{|c|c|c|c|c|c|c|}
\hline Publications & $\begin{array}{l}\text { Classroom } \\
\text { Type }\end{array}$ & Subject & $\begin{array}{l}\text { Cultural/Linguistic } \\
\text { Context }\end{array}$ & $\begin{array}{l}\text { Item Score } \\
\text { Mean }(S D) \\
\end{array}$ & $\begin{array}{l}\text { Scale Score } \\
\text { Mean }(S D) \\
\end{array}$ & Sample Size \\
\hline Dwyer et al. (2004) & F2F & $\begin{array}{l}\text { Communication } \\
\text { Studies }\end{array}$ & USA / English & - & $70.97(9.91)$ & 564 \\
\hline $\begin{array}{l}\text { Carlson, Dwyer, Bingham, Cruz, and } \\
\text { Prisbell (2006) }\end{array}$ & F2F & $\begin{array}{l}\text { Communication } \\
\text { Studies }\end{array}$ & USA / English & - & 70.92 (9.92) & 523 \\
\hline Prisbell et al. (2009) & $\mathrm{F} 2 \mathrm{~F}$ & Public Speaking & USA / English & - & $72.22(10.12)$ & 437 \\
\hline $\begin{array}{l}\text { Bingham, Carlson, Dwyer, and Prisbell } \\
\text { (2009) }\end{array}$ & $\mathrm{F} 2 \mathrm{~F}$ & Public Speaking & USA / English & - & 70.95 (9.96) & 542 \\
\hline Sidelinger and Booth-Butterfield (2010) & $\mathrm{F} 2 \mathrm{~F}$ & $\begin{array}{l}\text { Communication } \\
\text { Studies }\end{array}$ & USA / English & - & $59.27(11.82)$ & 434 \\
\hline Frisby \& Martin (2010) & $\mathrm{F} 2 \mathrm{~F}$ & $\begin{array}{l}\text { Communication } \\
\text { Studies }\end{array}$ & USA / English & - & $61.94(13.02)$ & 232 \\
\hline Sidelinger et al. (2011) & F2F & $\begin{array}{l}\text { Communication } \\
\text { Studies }\end{array}$ & USA / English & - & 67.37 (14.39) & 187 \\
\hline $\begin{array}{l}\text { Sidelinger, Bolen, Frisby, and McMullen } \\
\text { (2012) }\end{array}$ & $\mathrm{F} 2 \mathrm{~F}$ & Multidisciplinary & USA / English & - & $69.12(14.12)$ & 375 \\
\hline Sollito, Johnson, and Myers (2013) & F2F & $\begin{array}{l}\text { Communication } \\
\text { Studies }\end{array}$ & USA / English & $3.53(.67)$ & - & 170 \\
\hline Johnson (2013) & $\mathrm{F} 2 \mathrm{~F}$ & Multidisciplinary & USA / English & - & $66.95(10.58)$ & 345 \\
\hline Johnson \& LaBelle (2015) & $\mathrm{F} 2 \mathrm{~F}$ & Not Specified & USA / English & - & $62.38(12.10)$ & 351 \\
\hline $\begin{array}{l}\text { Myers, Goldman, Atkinson, Ball, Carton, } \\
\text { Tindage, and Anderson (2016) }\end{array}$ & F2F & $\begin{array}{l}\text { Communication } \\
\text { Studies }\end{array}$ & USA / English & - & $58.33(13.26)$ & 416 \\
\hline MacLeod, Yang, Zhu, and Shi (2017) & Online & Multidisciplinary & China / Mandarin & $3.63(.55)$ & $65.34(9.89)$ & 641 \\
\hline Hsu \& Huang (2017) & F2F & Multidisciplinary & $\begin{array}{c}\text { USA / English } \\
\text { (International Students) }\end{array}$ & - & $66.20(14.72)$ & 121 \\
\hline Xu et al. (2018) & $\begin{array}{c}\text { F2F } \\
\text { Blended }\end{array}$ & $\begin{array}{l}\text { Educational } \\
\text { Technology }\end{array}$ & USA / English & $\begin{array}{l}4.08(.80) \\
4.23(.74)\end{array}$ & $\begin{array}{l}73.35(9.01) \\
75.86(8.55)\end{array}$ & 22 \\
\hline Yang et al. (2018) & Online & Marxist Principles & China / Mandarin & $2.96(.91)$ & - & 284 \\
\hline
\end{tabular}

Note: Item mean score = average item score for 18 item construct; Scale mean score $=$ sum of responses for the 18 item construct. 
Based on a literature review of related studies, CCC describes a social interaction that exerts a positive influence on student learning. However, the social interaction of students may be problematic among large lecture hall courses and during computer-mediated communication. Therefore, the following research question was proposed:

What are college students' perceptions of CCC in the RST model of instruction compared to previous measurements of CCC among college students that have been documented in peerreviewed research?

\section{Participants and setting}

The participants of the study were 319 college students from a research-oriented, normal university in central China. The term normal university refers to a teacher-training institution of higher education. Participants were selected based on a convenience sample of eight classes enrolled in the same MSSC mathematics course, Linear Algebra. The course was compulsory, graded for credit, and lasted one semester. Fourteen participants' responses were omitted due to incompleteness. As a result, 305 ( 96\%) usable participant responses were complete and included for data analysis. The participants were all first year college students specialising in chemistry. Their age ranged from 16 to $22(M=19, S D=0.86)$ and the female-to-male ratio was about 3:1.

The subject of mathematics was chosen for two main reasons. First, mathematics' is regarded with a high level of importance in Chinese education systems. Therefore, analysis of important courses, such as mathematics, may provide the most generalisable findings to other academic courses. Second, the most qualified MSSC instructor available specialised in mathematics. The instructor had more than 10 years of teaching experience in higher education, which included 1 year of teaching experience with the MSSC. In support of the instructional process, 24 teaching assistants (8 graduate and 16 undergraduate students) worked under the direction of the instructor to conduct classes in the MSSC. The teaching assistants were selected based on a proficiency examination and, either a prerequisite of completing the MSSC course, or through recommendation by the instructor.

The design of the MSSC consisted of eight smart classrooms in the same building and on the same floor. This context was designed to allow the instructor to be approachable by all students, similar to the extent that an instructor is available to students who enroll in a large-scale, lecture hall course. Within each classroom, students were often organised into groups for practice activities. There were 60 groups in total. To support the group activities, the 24 teaching assistants were evenly distributed between the eight classrooms. This meant there was one graduate and two undergraduate students in each classroom. During group work activities, the instructor moved between classrooms to provide some F2F presence to the students that received computer-mediated instruction on that given day. Table 2 provides additional information regarding the participants and the classroom groupings.

Table 2

Demographic composition of the sample

\begin{tabular}{lcccc}
\hline \multirow{2}{*}{ Location ID } & \multicolumn{2}{c}{ Gender } & $\begin{array}{c}\text { Total Students } \\
(n=305)\end{array}$ & $\begin{array}{l}\text { Activity Groups } \\
(n=60)\end{array}$ \\
\cline { 2 - 3 } & Male $(n=78)$ & Female $(n=227)$ & 41 & 8 \\
Classroom 1 & 1 & 40 & 40 & 8 \\
Classroom 2 & 9 & 31 & 39 & 8 \\
Classroom 3 & 15 & 24 & 38 & 5 \\
Classroom 4 & 12 & 26 & 34 & 7 \\
Classroom 5 & 12 & 22 & 38 & 8 \\
Classroom 6 & 11 & 27 & 37 & 8 \\
Classroom 7 & 11 & 26 & 38 & 8 \\
Classroom 8 & 7 & 31 & & \\
\hline
\end{tabular}




\section{Instrumentation}

A mixed method research approach was used to collect quantitative and qualitative data. First, a survey was used to measure CCC. Then, individual semi-structured student interviews were conducted to triangulate the survey findings.

The quantitative data collection utilised the Connected Classroom Climate Inventory (Dwyer et al., 2004) to measure CCC and consisted of 18 items. Two representative items include: "The students in my class cooperate with one another" and "The students in my class feel comfortable with one another" (Table 4 for a complete list of items). All items were evaluated based on a 5-point Likert scale ranging from 1 (strongly disagree) to 5 (strongly agree) and Dwyer et al. (2004) reported alpha reliabilities of 0.94 for the CCC. For this study, the alpha reliability obtained from the survey was 0.91 .

The survey items were translated from English to Chinese so that the survey could be administered in the students' native language. Three researchers parallel translated (Guillemin, Bombardier, \& Beaton, 1993) the items with group discussion as a means for pre-assessing the translated draft. That is to say, whenever disagreement existed regarding the researchers' independent translation of an item, the items were further examined and discussed until agreement was reached between all three researchers. The completed translation then received bilingual assessment (Harkness \& Schoua-Glusberg, 1998) from an educational technology expert with over 20 years of university teaching experience in the USA and China. Feedback was collected from the expert and used to adjust the wording for several items to improve the overall readability of the survey. This process of English to Chinese translation was conducted in alignment with previous studies documenting successful translation and application of the Connected Classroom Climate Inventory (MacLeod, Yang, Zhu, \& Shi 2017; Yang et al., 2018).

The qualitative data collection was conducted based upon a pre-scripted interview protocol (CastilloMontoya, 2016) (see Appendix A). To ensure methodological rigor, three key components of Dwyer et al.'s (2004) definition of CCC guided the coding scheme (Ritchie, Lewis, Nicholls, \& Ormston, 2013) for qualitative examination toward behavioural, cognitive, and affective aspects of CCC. The three components of the coding scheme were cooperation (behavioural), supportiveness (cognitive), and bonding (affective). Cooperation refers to the act of "working together to accomplish shared goals" (Johnson \& Johnson, 2003, p. 786). Supportiveness refers to how one's network of social interaction can increase focus toward receiving content and interpreting cognitive meanings, as well as persistence of effort (Gibb, 1961; McGrath, Gutierrez, \& Valadez, 2000). Bonding refers to interpersonal interaction and companionship that positively support one's emotional well-being, self-esteem, and sense of security (Lee \& Robbins, 1995; Rook, 1984).

\section{Data collection and analysis procedure}

All data was collected during 2017, prior to final examinations at the end of the spring semester. After obtaining administrative approval to conduct the research, the survey was administered in paper format during a mid-class intermission break. The survey required approximately 5 to 10 minutes to complete. All participation in this study was both anonymous and voluntary.

Several days after the survey was administered, independent semi-structured interviews were conducted by the first author of this study. Eight students were selected based upon a review of information provided by the course teaching assistants. The selection criteria required each classroom to have one student representative. Furthermore, the selected student representative was required to possess average attendance and achievement in the course. The coding scheme used to describe the student interviewees is as follows: S-1 = student from classroom one; S-2 = student from classroom two; S-3 = student from classroom three, etc.

Each interview lasted approximately 20 to 45 minutes. The interviews were conducted in Chinese to allow students to respond in their native language. It was assumed that students would be more comfortable and provide greater depth in their description of phenomena when communicating in their native language. Interviews were audio recorded, then word processed into verbatim transcripts. Two researchers independently coded the interview transcripts based upon the coding scheme for qualitative instrumentation. Table 3 provides some representative examples of student quotes to illustrate the coding scheme procedures 
for aligning students' quotes with the CCC components (cooperation, supportiveness, bonding). Interrater reliability was good, with all Cohen's kappa coefficients were 0.82 (cooperation), 0.85 (suportiveness), and 0.91 (bonding), which were all about the threshold of 0.80 and suggested that the results were satisfactory (McHugh, 2012). The representative quotes selected for inclusion in this manuscript followed the same translation procedures as described above for quantitative survey item translation.

Table 3

Illustration of the coding scheme procedure

Representative student quotes

CCC components

After becoming familiar with the classroom, I felt free to propose my opinions, and others appeared interested to collaborate, too. (S-4)

Cooperation

My team and I used the technological tools of the classroom to work together and

(Behavioural)

find better ways of doing things. (S-3)

The leader in our learning group is so nice. Whenever I come across difficulties with my homework, I always seek assistance from him. (S-7)

Supportiveness

This class typically requires more out-of-class preparation. But, I enjoy being able to (Cognitive) help my peers when they have questions in class. (S-1)

My group mates are very nice people. I like to talk with them during the break. (S-5) I often talk with my group members. The more we talk, the more I find that we have so many interests in common. (S-7)

Bonding

(Affective)

\section{Results and discussion}

\section{Overall effect of the RST model on students' CCC}

To answer the research question, a survey assessed college students' perception of CCC in the RST instructional model. Table 4 provides an overview of mean scores and standard deviations for student responses. The results showed that the average CCC score was $3.79(S D=0.41)$. These findings suggest that roughly $95 \%$ of item mean scores range from 2.97-4.61, which, based on the 5-point Likert scale, describe a sample where the majority of students perceived mid-point or higher supportive and cooperative communication among students in the classroom.

Table 4

Descriptive statistics of students' responses to the CCC

\begin{tabular}{lcc}
\hline Items & $M$ & $S D$ \\
\hline 1. I feel a sense of security in my class. & 3.62 & 0.78 \\
2. I have common ground with my classmates. & 3.52 & 0.74 \\
3. I feel a strong bond with my classmates. & 3.33 & 0.84 \\
4. The students in my class share stories and experiences with one another. & 3.15 & 0.95 \\
5. The students in my class are friendly with one another. & 4.01 & 0.50 \\
6. The students in my class respect one another. & 4.06 & 0.50 \\
7. I feel included in class discussions in my class. & 3.74 & 0.72 \\
8. The students in my class are courteous with one another. & 4.03 & 0.52 \\
9. The students in my class praise one another. & 3.78 & 0.70 \\
10. The students in my class are concerned about one another. & 3.84 & 0.66 \\
11. The students in my class smile at one another. & 3.96 & 0.57 \\
12. The students in my class engage in small talk with one another. & 3.82 & 0.71 \\
13. The students in my class are non-judgmental with one another. & 3.76 & 0.69 \\
14. The students in my class laugh with one another. & 3.87 & 0.66 \\
15. The students in my class are supportive of one another. & 4.01 & 0.47 \\
16. The students in my class show interest in what one another is saying. & 3.73 & 0.65 \\
17. The students in my class cooperate with one another. & 3.98 & 0.52 \\
18. The students in my class feel comfortable with one another. & 4.06 & 0.46 \\
\hline
\end{tabular}


Comparison to previous measurement of CCC

As shown in Table 1, previous studies have reported CCC in two ways: item mean scores and/or scale mean scores. The current study provides both to enable compatibility with all types of previous reporting. In comparison to previous research, the mean scale score reported in the RST model for instruction $(M=68.27$, $S D=7.34)$ was within the range reported $(M=66.40-80.41)$ by 30 traditional F2F communication classes that were examined during instrument development (Dwyer et al., 2004), although near the lower end of that range. In contrast to the broader documentation of CCC in peer-reviewed research (see Table 1), these findings were near the middle of what the majority of studies have reported $(M=58.33-75.86)$.

Previous studies benchmarked three general reference points to further interpret the CCC scores reported in this study. First, to describe the effect of class size, Sidelinger, Bolen, McMullen, \& Nyeste (2012) explored traditional F2F classes and found that large classes $(M=60.93, S D=15.16)$ reported significantly lower levels of CCC compared to small classes $(M=71.31, S D=12.96)$. However, a significant difference was not observed between small and medium sized classes $(M=65.39, S D=15.31)$. This result was based on the following classroom categorisation: small $=1-25$ students; medium $=26-50$ students; large $=$ or $>$ 51 students. Based upon the categorisation of Sidelinger et al. (2012), all classes in this study were medium sized and the mean scale score of our study was similar to the medium class size CCC reported by Sideliner et al. (2012). These findings provide preliminary evidence suggesting that the RST model of instruction may be capable of stimulating students' CCC equal to that of traditional F2F instruction. Future studies should examine this result within a comparative research methodology.

Second, one comparative study examined students' perception of CCC among F2F and blended classrooms. While the typical blended classroom does not describe the RST model, it may offer an important perspective since both rely on an instructor who is not always physically available. Xu et al. (2018) found no significant difference among students' perception of CCC between the F2F classroom $(M=4.08, S D=0.80)$ and the blended classroom $(M=4.23, S D=0.74)$. These item mean scores are both higher than those found in this study $(M=3.79, S D=0.41)$. It should be noted that the previous study by the Xu et al. (2018) explored graduate students in one of their discipline-specific courses, which may also explain higher levels of social interaction compared to what was observed among our sample of first-year college students enrolled in a compulsory mathematics course. In addition, Xu et al. (2018) utilised a sample, that would be categorised as a small class (1-25 students), which may also explain the slightly higher results.

Finally, two previous studies that examined CCC among Chinese college students (MacLeod, Yang, Zhu, \& Shi, 2017; Yang et al., 2018) represented similar cultural characteristics to those of the participants of this study. Both studies reported lower item mean scores for CCC $(M=2.96-3.63)$ than the present study. However, CCC was measured in cloud classrooms, which is a fully online learning environment. This difference may explain the slightly lower scores, as students' perception of connectedness has been previously reported lower along fully online environments in comparison to traditional face-to-face and blended classrooms (Ritter et al., 2010). Therefore, the results of this study remain within a consistent range of previously reported scores among our sample demographics. The data from student interviews provided evidence that supports the triangulation of the quantitative survey. Table 5 provides an overview of the frequency of related CCC component statements from the eight interviewees.

Table 5

Overview of the qualitative analysis

\begin{tabular}{ccccc}
\hline Participant ID & Cooperation & Supportiveness & Bonding & Total \\
\hline S-1 & 1 & 1 & 2 & 4 \\
S-2 & 2 & 2 & 0 & 4 \\
S-3 & 1 & 3 & 2 & 6 \\
S-4 & 4 & 2 & 2 & 8 \\
S-5 & 1 & 2 & 4 & 7 \\
S-6 & 3 & 1 & 2 & 6 \\
S-7 & 0 & 4 & 1 & 5 \\
S-8 & 0 & 2 & 0 & 2 \\
\hline Total & 12 & 17 & 13 & 42 \\
\hline
\end{tabular}




\section{Cooperation}

Statements aligning the behavioural component of cooperation were mentioned by six out of eight student interviewees. Students seemed to like working together with their fellow group members in class. For example, S-2 claim, "I often work with [student name] in order to finish our assignments. Our combined effort is much more effective.” This type of statement was common among interviewees and very clearly resonated with Johnson and Johnson's (2003) definition of cooperation. Additionally, the graduate student teaching assistants' active participation during class activities, stage 6 (elicit performance) of Gagné's $(1965,1985)$ nine instructional events, appeared to also make the students feel more cooperative with one another. A representative quote from S-6 describes this scenario:

Our teaching assistants often walked around the class and were readily available to offer help. When my group was discussing problems, one of the teaching assistants very frequently joined into the discussion. With their guidance, the discussion atmosphere became more engaging.

However, when searching for rival explanations and negative cases of cooperation within the qualitative data, the transcripts for S-7 and S-8 were targeted because they did not include statements aligning the CCC component of cooperation (Table 5). S-7 stated, "Since my team leader and I became friends in class, I have wanted to behave as smart as him." Additionally, S-8 mentioned, "After becoming familiar with the group atmosphere, I always wanted to contribute more than my other group members." While both of these comments appeared to describe somewhat of a positive motivational influence, they did not fit the coding scheme for cooperation. In contrast, these quotes could be more accurately described as competition, whereby, students illustrated interest in the enhancement of personally favorable power differences, and a conceptual desire to win (Johnson, 2003). Future research should explore classroom reward systems and organisational strategies that ensure such competitive relationships only maintain positive motivation and do not escalate to include negative components of competition that may deter cooperation, such as deceptive communication, tactics of coercion, or one’s obstruction of others' success (Johnson, 2003).

\section{Supportiveness}

In general, supportiveness was the most commonly stated CCC component within the qualitative coding scheme. Supportiveness described one's network of social interaction increasing focus toward receiving content, interpreting cognitive meanings, and persistence of effort (Gibb, 1961; McGrath et al., 2000). All eight student interviewees mentioned statements that aligned the coding scheme for cognitive supportiveness. For example, S-7 said:

If the lead instructor was not giving the lecture in my class, I often encountered some difficulties with sound transmission. Also, if I didn't come to class adequately prepared, it was difficult to keep pace with the course. However, my team mates were so nice. Whenever I couldn't understand something, they were always available to help me.

Only two negative case statements were identified in relation to the CCC component of supportiveness within the qualitative data. S-6 stated, "I was sick and didn't attend the first class. This type of teaching method was different and made it really difficult for me to know what to do at first," which described an uncomfortable situation which was not simply resolved by peer support. Additionally, S-1 mentioned, “As a group leader, many of my group members require help in class, so now I am required to study hard before every class, otherwise I don't know how to answer their questions.” This statement indicated that the more advanced students, in this case the group leader, shoulders some additional responsibilities in the absence of a F2F instructor in the RST model. Both of these student responses appeared neutral-toned, however, it was clear that they more closely resembled a theme of defensiveness rather than supportiveness. Defensiveness describes behaviours and communication which occur when an individual perceives there is a threat, whereby they divert some of their attention away from the assigned tasks in order to defend themselves (Gibb, 1961).

\section{Bonding}

Six out of eight interviewees mentioned statements that aligned the affective CCC component of bonding. Bonding refers to interpersonal interaction and companionship that positively supports one's emotional well-being, self-esteem, and sense of security (Lee \& Robbins, 1995; Rook, 1984). For instance, a representative quote from $\mathrm{S}-5$ is as follows: 
During the class breaks we all like to talk. I don't remember who began complaining about having to take too many courses this term. But, all the students in our learning group begin to share a similar experience, which was comforting.

In this sense, the CCC component of bonding is described to be enabled by the short structured breaks given to students when switching between the three class periods that facilitate different learning processes of Gagné’s (1965, 1985) nine instructional events (Figure 2).

Cultural and gender influences were identified as providing negative cases of bonding within the qualitative data. For example, S-2 mentioned "In my class, most students are females, even the three teaching assistants. I know this is the common situation in a normal university, but I really feel left out of the class sometimes." Additionally, S-8 stated, "I'm from [a minority region of China], and therefore, I can't speak Mandarin Chinese as fluently as my peers. I was afraid to talk with other students at first and this made me feel very isolated." Both of these statements did not align with the CCC coding scheme. In contrast they more accurately resembled loneliness, which describes unwanted isolation that is distressing such as through the association with feelings of sadness, anxiety, anger, boredom, or feelings of marginality (Rook, 1984).

In addition to the coded CCC analysis of qualitative data, some representative responses were included to illustrate college students' overall experience with the RST model of instruction:

I still remember when I first entered into the [classroom]. I felt so excited when I saw the classroom environment. [The classroom] is so different from my high school classrooms. In accordance to the instructor's direction, I joined a team. (Student paused and smiled.) At first, I just smiled at them and didn't know what to say. However, now we chat very often. When I come across learning difficulties, I always turned to our teaching assistant for help. He is such a nice boy and I think we all enjoyed making friends with him. (S-4)

This quote provides the insight that, even before the process of instruction had begun, the novelty of the educational environment captured the attention of some students. While the novelty effect of new technology has been observed to fade overtime (e.g., Serow \& Callingham, 2011), the student's description illustrates a feeling that stimulated happiness and personal interest in communication with other students and the teaching assistant. From a CCC perspective, this representative quote also depicts some initial feelings of anxiety regarding peer collaboration, particularly, in relation to the group formation process. However, these feelings appeared to dissipate over time. Additionally, the student's relationship with the teaching assistant (who is a student at the university) was highlighted with appreciation and was suggested to be beneficial for the student's learning process.

The following quote from S-6 provides another representative illustration of CCC in the RST model:

I feel that I belong with my group and believe that we can learn together. The concept of our instructor not always teaching in our classroom is something that I have become used to over time. In fact, now I don't really feel it is any different. I enter the same classroom, at the required time, and say hello to the same classmates. The difference is that now I have three nice teaching assistants instead of one instructor. It is still a very comfortable environment for me to learn.

The above-mentioned quote describes a strong personal relationship to peers, regardless of the instructor's presence during the F2F instruction. While the altered instructor presence was recognised as an initial cause for concern, this condition was described as normalising overtime and appeared to be accepted by the student. After initial adjustment, the student reflected as being content with the exchange of "three nice teaching assistants” in replacement of the F2F instructor.

This quote also suggests that the influence of an instructor may not inhibit the development of student-tostudent social interaction in classrooms, which is in alignment with other findings reported previously (Frisby \& Martin, 2010; Sidelinger et al., 2011). As little research has been conducted with Dwyer et al.'s (2004) student-to-student interpretation of CCC in technology-supported learning environments, this study contributes initial evidence suggesting that positive perceptions of CCC can exist in the RST model of 
instruction. These results also strengthen the findings from previous research that suggested the level of CCC can be similar between traditional face-to-face and blended learning environments (Ritter et al., 2010; Xu et al., 2018).

\section{Conclusion}

In an effort to address the challenge of increasing instructor efficiency without reducing or eliminating students' interactive face-to-face experiences, this study designed, developed, and implemented the rotational synchronous teaching (RST) model of instruction, as well as examined students' CCC (Dwyer et al., 2004) within this particular instructional context. The RST model of instruction is based upon Gagné's $(1965,1985)$ theory of instruction and integrates synchronously connected smart classrooms with an asynchronous cloud classroom via flipped classroom approach. In addition, the RST model evenly distributes the instructor's F2F presence between classrooms and incorporates teaching assistants to facilitate classroom processes of discussion, practice, and reflection. This unique integration of learning space and separation of instructional responsibilities provides completely new possibilities to support learning in large student groups, which may provide an alternative to traditional large lecture hall environments.

However, an expansion of new instructional models should not be considered without empirical evaluation of instructional effectiveness. This study was designed to thoroughly document the instruction model and to conduct a preliminary examination of effectiveness from a communication perspective. Considering the negative effects that computer-mediated communication can impose on social relationships (Walther \& Parks, 2002), this mixed methods study focused on examining student-to-student social interaction, which is a central part of learning in the absence of a F2F instructor. Overall, the students survey responses indicated that perception of CCC in the RST model was generally within a similar range of previous findings reported in peer-reviewed journals. The interview data further described students' feeling of excitement toward social interaction and highlighted the novelty of the utilised technologies in the RST model of instruction. Additionally, students expressed a sense of belonging to their peer groups. These findings indicated that despite a periodic absence of the instructor's F2F presence, utilisation of an appropriate pedagogical approach could still cultivate a learning environment that stimulates CCC, which led to a positive and supportive student-to-student communication environment (Dwyer et al., 2004).

To conclude, despite the beneficial capabilities that have been conceptualised in this study, there are still some challenges for such an instructional model, which require further empirical investigation. For example, managing the tendencies of students' competitive instinct, overcoming the defensiveness that students may perceive as adjusting to the new instructional approach, and reducing the feelings of isolation among students facing integration difficulties within group settings. Future research is needed to explore the organisational design strategies and reward systems that minimise these types of challenges identified in the present study. Additionally, this study documents the RST model and contributes the first empirically tested evidence, suggesting that students' perception of CCC remains within the range of previously reported studies exploring CCC in traditional F2F instruction settings. Researchers and practitioners are encouraged to begin utilising the RST model and contribute knowledge that expands our understanding of its effectiveness.

\section{Implications}

The main contribution of this study is the development and documentation of the RST model. The proposed RST model utilises a blended learning approach with three phases, including pre-class, in-class, and postclass instructional events. Additionally, the RST model improves capabilities for addressing large lecture hall environments by connecting multiple synchronous smart classrooms, rotating the schedule of the instructors teaching between classroom locations, and incorporating teaching assistant to facilitate classroom processes. Instructors, teaching assistants, and students all must assume different roles and responsibilities, in order to exercise this instructional approach. Therefore, the preparation and participation of the instructor, teaching assistants, and students are essential for the implementation of the RST model, particularly for transitioning between the F2F classroom and cloud classroom, as well as for transitioning between F2F instruction and synchronous computer-mediated instructional delivery. Based upon the CCCrelated findings of this study, the RST model should consider the following teaching strategies: 
- customising instructions, learning activities, grading procedures, reward schemes, etc. to encourage cooperative interaction among peers, as well as discourage problematic competitive beliefs and behaviours;

- developing appropriate training modules and protocols to inform instructors and teaching assistants of the importance of encouraging proactive outreach to students during the early stages of the semester, when adjusting to the instructional model; and

- considering and monitoring individual social characteristcs of students more closely during the grouping processes. Furthermore, instructors and teaching assistants should be given resources to help them identify signs of loneliness, as well as to implement strategies that encourage the integration of diverse student populations in working group settings.

\section{Limitations and future research}

When considering the contribution of this research, several limitations should be recognised. This mixed method study focused on CCC among a monocultural sample of Chinese college students. Future research should explore the comparison of perceptions between differing national cultures, as critical differences between cultural perceptions have been noted in other technology-supported learning environments (e.g., MacLeod \& Yang, 2018; MacLeod, Yang, \& Xiang, 2017). Further, to expand the application of the RST model, empirical research is needed within different levels of education, particularly K-12 education. One of the most significant contributions the MSSC provides is an ability to address teacher shortages, which are well-recognised in K-12 settings (Aragon, 2016; Ingersoll \& Perda, 2009). Therefore, this is an important future direction for validating and expanding usage of the RST model. When exploring primary and secondary education levels, other key research variables should be reconsidered. For example, the parents' perspective of instruction may be an important factor that impacts acceptance among younger participants (Zhu, Yang, MacLeod, Shi, \& Wu, in press).

In addition, beyond examination of CCC, the concepts of synchronous computer-mediated instruction and teaching assistant-led group work activities are significant changes from the traditional processes of instruction. These are important aspects of the RST model which require further exploration to expand conceptual understanding. Other critical associations with CCC in the RST model, such as the cognitive, self-regulated, and affective learning (Frisby \& Martin, 2010; Johnson, 2009; Prisbell et al., 2009; Sidelinger \& Booth-Butterfield, 2010) should also be examined, as theoretically they have been linked in traditional F2F environments. However, these variables have yet to be examined in combination with CCC in any technology-supported learning environment.

\section{Acknowledgements}

This work was supported by the Key Projects of Philosophy and Social Research, Ministry of Education of China under grant \#14JDZ044.

\section{References}

Alelaiwi, A., Alghamdi, A., Shorfuzzaman, M., Rawashdeh, M., Hossain, M. S., \& Muhammad, G. (2015). Enhanced engineering education using smart class environment. Computers in Human Behavior, 51(B), 852-856. https://doi.org/10.1016/j.chb.2014.11.061

Aragon, S. (2016). Teacher shortages: What we know. Denver, CO: Education Commission of the States. Retrieved from https://files.eric.ed.gov/fulltext/ED565893.pdf

Baepler, P., Walker, J. D., \& Driessen, M. (2014). It’s not about seat time: Blending, flipping, and efficiency in active learning classrooms. Computers \& Education, 78, 227-236. https://doi.org/10.1016/j.compedu.2014.06.006

Bingham, S. G., Carlson, R. E., Dwyer, K. K., \& Prisbell, M. (2009). Student misbehaviors, instructor responses, and connected classroom climate: Implications for the basic course. Basic Communication Course Annual, 21(7), 30-68. Retrieved from http://ecommons.udayton.edu/bcca/vol21/iss1/7

Bonk, C., \& Graham, C. (Eds.). (2005). The handbook of blended learning: Global perspectives, local designs. New York, NY: Pfeiffer. 
Carlson, R. E., Dwyer, K. K., Bingham, S. G., Cruz, A. M., \& Prisbell, M. (2006). Connected classroom climate and communication apprehension: Correlations and implications of the basic course. Basic Communication Course Annual, 18(6), 1-27. Retrieved from http://ecommons.udayton.edu/bcca/vol18/iss1/6

Castillo-Montoya, M. (2016). Preparing for interview research: The interview protocol refinement framework. The Qualitative Report, 21(5), 811-831. Retrieved from http://nsuworks.nova.edu/tqr/vol21/iss5/2

Dwyer, K. K., Bingham, S. G., Carlson, R. E., Prisbell, M., Cruz, A. M., \& Fus, D. A. (2004). Communication and connectedness in the classroom: Development of the connected classroom climate inventory. Communication Research Reports, 21(3), 264-272. https://doi.org/10.1080/08824090409359988

Fassinger, P. A. (1996). Professors' and students' perceptions of why students participate in class. Teaching Sociology, 24(1), 25-33. Retrieved from http://www.jstor.org/stable/1318895

Fassinger, P. A. (1997). Classes are groups: Thinking sociologically about teaching. College Teaching, 45(1), 22-25. https://doi.org/10.1080/87567559709596184

Frisby, B. N., \& Martin, M. M. (2010). Instructor-student and student-student rapport in the classroom. Communication Education, 59(2), 146-164. https://doi.org/10.1080/03634520903564362

Gagné, R. M. (1965). The conditions of learning and theory of instruction. (1st ed.). New York, NY: Holt, Rinehart \& Winston.

Gagné, R. M. (1985). The conditions of learning and theory of instruction (4th edition). New York, NY: Holt, Rinehart \& Winston.

Gibb, J. (1961). Defensive communication. Journal of Communication, 11(3), 141-148. https://doi.org/10.1111/j.1460-2466.1961.tb00344.x

Guillemin, F., Bombardier, C., \& Beaton, D. (1993). Cross-cultural adaptation of health-related quality of life measures: Literature review and proposed guidelines. Journal of Clinical Epidemiology, 46(12), 1417-1432. https://doi.org/10.1016/0895-4356(93)90142-N

Hancock, T. M. (2010). Use of audience response systems for summative assessment in large classes. Australasian Journal of Educational Technology, 26(2), 226-237. https://doi.org/10.14742/ajet.1092

Harkness, J. A., \& Schoua-Glusberg, A. (1998). Questionnaires in translation. In J. A. Harkness (Ed.), Cross-cultural survey equivalence (pp. 87-126) Mannheim: Wiley-Interscience. https://nbn-resolving.de/urn:nbn:de:0168-ssoar-49733-1

Hsu, C. -F., \& Huang, I. -T. (2017). Are international students quiet in class? The influence of teacher confirmation on classroom apprehension and willingness to talk in class. Journal of International Students, 7(1), 38-52.

Huang, R., Yang, J., \& Hu, Y. (2012). From digital to smart: The evolution and trends of learning environment. Open Education Research, 1, 75-84.

Ingersoll, R. M., \& Perda, D. (2009). The mathematics and science teacher shortage: Fact and myth. Philadelphia, PA: Consortium for Policy Research in Education, University of Pennsylvania.

Johnson, D. I. (2009). Connected classroom climate: A validity study. Communication Research Reports, 26(2), 146-157. https://doi.org/10.1080/08824090902861622

Johnson, D. I. (2013). Student in-class texting behavior: Associations with instructor clarity and classroom relationships. Communication Research Reports, 30(1), 57-62. https://doi.org/10.1080/08824096.2012.723645

Johnson, D. W. (2003). Social interdependence: Interrelationships among theory, research, and practice. American Psychologist, 58(11), 934-945. https://doi.org/10.1037/0003-066X.58.11.934

Johnson, D. W., \& Johnson, R. T. (2003). Cooperation and the use of technology. In D. H. Jonassen (Ed.), Handbook of research on educational communications and technology (2nd ed., pp. 785-811). Mahwah, NJ: Taylor \& Francis.

Johnson, Z. D., \& LaBelle, S. (2015). Examining the role of self-disclosure and connectedness in the process of instructional dissent: A test of the instructional beliefs model. Communication Education, 64(2), 154-170. https://doi.org/10.1080/03634523.2014.978800

Lai, K. W. (2011). Digital technology and the culture of teaching and learning in higher education. Australasian Journal of Educational Technology, 27(8), 1263-1275. https://doi.org/10.14742/ajet.892

Lee, R. M., \& Robbins, S. B. (1995). Measuring belongingness: The social connectedness and the social assurance scales. Journal of Counseling Psychology, 42(2), 232-241. https://doi.org/10.1037/00220167.42.2.232 
MacLeod, J., \& Yang, H. H. (2018). Intercultural computer-supported collaborative learning: Theory and Practice. In R. Z. Zheng (Ed.), Digital technologies and instructional design for personalized learning (pp. 80-97). Hershey, PA: IGI Global. https://doi.org/10.4018/978-1-5225-3940-7.ch004

MacLeod, J., Yang, H. H., \& Xiang, Z. (2017). Understanding college students’ intrinsic motivation and social interdependence in intercultural computer-supported collaborative learning between USA and China. The Asia-Pacific Education Researcher, 26(3-4), 205-217. https://doi.org/10.1007/s40299$\underline{017-0341-6}$

MacLeod, J., Yang, H. H., Zhu, S., Li, Y. (2018). Understanding students' preferences toward the smart classroom learning environment: Development and validation of an instrument. Computers \& Education, 122, 80-91. https://doi.org/10.1016/j.compedu.2018.03.015

MacLeod, J., Yang, H. H., Zhu, S., \& Shi, Y. (2017). Technological factors and student-to-student connected classroom climate in cloud classrooms. Journal of Educational Computing Research, (online first). https://doi.org/10.1177/0735633117733999

McGrath, P. B., Gutierrez, P. M., \& Valadez, I. M. (2000). Introduction of the college student social support scale: Factor structure and reliability assessment. Journal of College Student Development, 41(4), 415-426.

McHugh, M. L. (2012). Interrater reliability: The kappa statistic. Biochemia Medica, 22(3), 276-282. https://doi.org/10.11613/BM.2012.031

Ministry of Education, People’s Republic of China. (2017). Work points for information and communication technology in education. [in Chinese]. Retrieved from http://www.moe.edu.cn/srcsite/A16/s3342/201702/t20170221_296857.html

Myers, S. A., Goldman, Z. W., Atkinson, J., Ball, H., Carton, S. T., Tindage, M. F., \& Anderson, A. O. (2016). Student civility in the college classroom: Exploring student use and effects of classroom citizenship behavior. Communication Education, 65(1), 64-82. https://doi.org/10.1080/03634523.2015.1061197

Pishva, D., \& Nishantha, G. G. D. (2008). Smart classrooms for distance education and their adoption to multiple classroom architecture. Journal of Networks, 3(5), 54-64.

Prisbell, M., Dwyer, K. K., Carlson, R. E., Bingham, S. G., \& Cruz, A. M. (2009). Connected classroom climate and communication in the basic course: Associations with learning. Basic Communication Course Annual, 21(11), 151-172. Retrieved from http://ecommons.udayton.edu/bcca/vol21/iss1/11

Ritchie, J., Lewis, J., Nicholls, C. M., \& Ormston, R. (Eds.). (2013). Qualitative research practice: A guide for social science students and researchers. London: Sage Publications.

Ritter, C., Polnick, B., Fink, R., \& Oescher, J. (2010). Classroom learning communities in educational leadership: A comparison study of three delivery options. The Internet and Higher Education, 13(12), 96-100. https://doi.org/10.1016/j.iheduc.2009.11.005

Rook, K. S. (1984). Promoting social bonding: Strategies for helping the lonely and socially isolated. American Psychologist, 39(12), 1389-1407. https://doi.org/10.1037/0003-066X.39.12.1389

Serow, P., \& Callingham, R. (2011). Levels of use of interactive whiteboard technology in the primary mathematics classroom. Technology, Pedagogy, \& Education, 20(2), 161-173. https://doi.org/10.1080/1475939X.2011.588418

Shen, C. W., Wu, Y. C. J., \& Lee, T. C. (2014). Developing a NFC-equipped smart classroom: Effects on attitudes toward computer science. Computers in Human Behavior, 30, 731-738. https://doi.org/10.1016/j.chb.2013.09.002

Shi, Y., Xie, W., Xu, G., Shi, R., Chen, E., Mao, Y., \& Liu, F. (2003). The smart classroom: Merging technologies for seamless tele-education. IEEE Pervasive Computing, 2(2), 47-55. https://doi.org/10.1109/MPRV.2003.1203753

Sidelinger, R. J., Bolen, D. M., Frisby, B. N., \& McMullen, A. L. (2011). When instructors misbehave: An examination of student-to-student connectedness as a mediator in the college classroom. Communication Education, 60(3), 340-361. https://doi.org/10.1080/03634523.2011.554991

Sidelinger, R. J., Bolen, D. M., Frisby, B. N., \& McMullen, A. L. (2012). Instructor compliance to student requests: An examination of student-to-student connectedness as power in the classroom. Communication Education, 61(3), 290-308. https://doi.org/10.1080/03634523.2012.666557

Sidelinger, R. J., \& Booth-Butterfield, M. (2010). Co-constructing student involvement: An examination of teacher confirmation and student-to-student connectedness in the college classroom. Communication Education, 59(2), 165-184. https://doi.org/10.1080/03634520903390867

Sollitto, M., Johnson, Z. D., \& Myers, S. A. (2013). Students’ perceptions of college classroom connectedness, assimilation, and peer relationships. Communication Education, 62(3), 318-331. https://doi.org/10.1080/03634523.2013.788726 
Walther, J. B., \& Parks, M. (2002). Cues filtered out, cues filtered in: Computer-mediated communication and relationships. In M. L. Knapp \& J. A. Daly (Eds.), Handbook of interpersonal communication (pp. 529-563). Thousand Oaks, CA: Sage.

Xu, J., Yang, H. H., \& MacLeod, J. (2018). STEP on connected classroom climate in hybrid learning environment. International Journal of Innovation and Learning, 23(4), 430-443. https://doi.org/10.1504/IJIL.2018.10011969

Yang, H. H., Feng, L., \& MacLeod, J. (2018). Understanding students’ acceptance of cloud classrooms: Integrating UTAUT and connected classroom climate. Journal of Educational Computing Research. (online first) https://doi.org/10.1177/0735633117746084

Yang, H. H., Zhu, S., \& MacLeod, J. (2016, July). Collaborative teaching approaches: Extending current blended learning models. In S. Cheung, L. Kwok, J. Shang, A. Wang, \& R. Kwan (Eds.), International Conference on Blended Learning (pp. 49-59). Cham, Switzerland: Springer. https://doi.org/10.1007/978-3-319-41165-1_5

Yang, H. H., Zhu, S., MacLeod, J. (2018). Promoting education equity in rural and underdeveloped areas: Cases of computer-supported collaborative teaching in China. Eurasua Journal of Mathematics, Science and Technology Education, 14(6), 1393-1405. https://doi.org/10.29333/ejmste/89841

Zhu, S., Yang, H. H., MacLeod, J., Shi, Y., \& Wu, D. (in press). Parents’ and students’ attitudes toward tablet integration in schools. The International Review of Research in Open and Distributed Learning.

Corresponding author: Harrison Hao Yang, harrison.yang@oswego.edu

Australasian Journal of Educational Technology (c) 2019.

Please cite as: Li, Y, Yang, H. H., MacLeod, J., \& Dai, J. (2019). Developing the rotational synchronous teaching (RST) model: Examination of the connected classroom climate. Australasian Journal of Educational Technology, 35(1), 116-134. https://doi.org/10.14742/ajet.4010 


\section{Appendix A \\ Qualitative interview: Pre-script and interview questions}

Script prior to the interview:

Hello! My name is [interviewer name], I'm a doctoral candidate studying at [department name] here at [university name]. I'd like to thank you for taking the time to chat with me today. As previously described by your teaching assistant, I am working in a team that conducts research related to the alternative form of instruction in which you participated this semester. Our study seeks to understand your experience in the multiple synchronous smart classroom learning environment. The study also seeks to understand the social interaction and depth of relationships between students in this alternative instructional model. The purpose of our research is to begin documenting the students' perspective of the instructional model to support improvements in the design, development, and implementation of future teaching initiatives.

The interview will last for approximately 20 minutes, during which I will be asking you some openended questions. Please feel relaxed, as there are no right or wrong answers to the questions. Additionally, everything you say will remain confidential. The information you share today will only be used for educational research, and your specific opinions or perspectives will not be shared with your instructor or is in any way connected to your grades in this course.

If it is okay with you, I would like to audio record our conversation with my smart phone. I would like to reassure you again that the recording is anonymous, which means that the recording will not be marked or labeled with any of your personal identifiable information. Are you okay with me recording our conversation today? Yes No

If yes: Thank you! Please let me know if at any point you want me to turn off the recording device or keep something you said off the record.

If no: Thank you for letting me know. I will only take notes of our conversation.

Before we begin the interview, do you have any questions?

[discuss interviewee questions]

Please feel free to stop me and ask a question if one or more questions come to mind during the interview at any point. I am very happy to help clarify any questions you may have.

Let's begin ... [move to the interview questions]

\begin{tabular}{|l|l|}
\hline $\begin{array}{l}\text { Overall } \\
\text { experience }\end{array}$ & $\begin{array}{l}\text { Can you please try to describe your overall experience in the MSSC? } \\
\text { What was your first impression upon entering the learning environment? } \\
\text { How does this class compare to other large lecture hall courses you have taken? } \\
\text { What is your impression of the differences in this instructional design? }\end{array}$ \\
\hline $\begin{array}{l}\text { Connected } \\
\text { Classroomate }\end{array}$ & $\begin{array}{l}\text { Can you please describe your relationship with classmates in the MSSC? } \\
\text { Do you engage in friendly conversation with your peers in the classroom? } \\
\text { How would you describe your cooperation with your classmates? } \\
\text { Are youportive of your peers learning, and do you feel supported in return? } \\
\text { What type of bond do you share with the other students in your class? }\end{array}$ \\
\hline
\end{tabular}

